\title{
Research Article \\ Stabilities of Cubic Mappings in Fuzzy Normed Spaces
}

\author{
Ali Ghaffari and Ahmad Alinejad \\ Department of Mathematics, Semnan University, P.O. Box 35195-363, Semnan, Iran \\ Correspondence should be addressed to Ali Ghaffari, aghaffari@semnan.ac.ir \\ Received 15 January 2010; Revised 19 April 2010; Accepted 11 May 2010 \\ Academic Editor: T. Bhaskar
}

Copyright (C) 2010 A. Ghaffari and A. Alinejad. This is an open access article distributed under the Creative Commons Attribution License, which permits unrestricted use, distribution, and reproduction in any medium, provided the original work is properly cited.

Rassias (2001) introduced the pioneering cubic functional equation in the history of mathematical analysis: $f(x+2 y)-3 f(x+y)+3 f(x)-f(x-y)=6 f(y)$ and solved the pertinent famous Ulam stability problem for this inspiring equation. This Rassias cubic functional equation was the historic transition from the following famous Euler-Lagrange-Rassias quadratic functional equation: $f(x+y)-2 f(x)+f(x-y)=2 f(y)$ to the cubic functional equations. In this paper, we prove the Ulam-Hyers stability of the cubic functional equation: $f(x+3 y)-3 f(x+y)+3 f(y-x)-f(x-3 y)=$ $48 f(y)$ in fuzzy normed linear spaces. We use the definition of fuzzy normed linear spaces to establish a fuzzy version of a generalized Hyers-Ulam-Rassias stability for above equation in the fuzzy normed linear space setting. The fuzzy sequentially continuity of the cubic mappings is discussed.

\section{Introduction}

Studies on fuzzy normed linear spaces are relatively recent in the field of fuzzy functional analysis. The notion of fuzzyness has a wide application in many areas of science. In 1984, Katsaras [1] first introduced a definition of fuzzy norm on a linear space. Later, several notions of fuzzy norm have been introduced and discussed from different points of view $[2,3]$. Concepts of sectional fuzzy continuous mappings and strong uniformly convex fuzzy normed linear spaces have been introduced by Bag and Samanta [4]. Bag and Samanta [5] introduced a notion of boundedness of a linear operator between fuzzy normed spaces, and studied the relation between fuzzy continuity and fuzzy boundedness. They studied boundedness of linear operators over fuzzy normed linear spaces such as fuzzy continuity, sequential fuzzy continuity, weakly fuzzy continuity and strongly fuzzy continuity.

The problem of stability of functional equation originated from a question of Ulam [6] concerning the stability of group homomorphism in 1940. Hyers gave a partial affirmative 
answer to the question of Ulam for Banach spaces in the next year [7]. Let $X$ and $Y$ be Banach spaces. Assume that $f: X \rightarrow Y$ satisfies $\|f(x+y)-f(x)-f(y)\| \leq \epsilon$ for all $x, y \in X$ and some $\epsilon>0$. Then, there exists a unique additive mapping $T: X \rightarrow Y$ such that $\|f(x)-T(x)\| \leq \epsilon$ for all $x \in X$. Hyers' theorem was generalized by Aoki [8] for additive mappings. In 1978, a generalized solution for approximately linear mappings was given by Th. M. Rassias [9]. He considered a mapping $f: X \rightarrow Y$ satisfying the condition

$$
\|f(x+y)-f(x)-f(y)\| \leq \epsilon\left(\|x\|^{p}+\|y\|^{p}\right)
$$

for all $x, y \in X$, where $\epsilon \geq 0$ and $0 \leq p<1$. This result was later extended to all $p \neq 1$.

In 1982, J. M. Rassias [10] gave a further generalization of the result of Hyers and prove the following theorem using weaker conditions controlled by a product of powers of norms. Let $f: E \rightarrow E^{\prime}$ be a mapping from a normed vector space $E$ into a Banach space $E^{\prime}$ subject to the inequality

$$
\|f(x+y)-f(x)-f(y)\| \leq \epsilon\left(\|x\|^{p}\|y\|^{p}\right)
$$

for all $x, y \in E$, where $\epsilon \geq 0$ and $0 \leq p<1 / 2$. Then there exists a unique additive mapping $L: E \rightarrow E^{\prime}$ which satisfies

$$
\|f(x)-L(x)\| \leq \frac{\epsilon}{2-2^{2 p}}\|x\|^{2 p}
$$

for all $x \in E$. The above mentioned stability involving a product of powers of norms is called Ulam-Gavruta-Rassias stability by various authors [11-25].

In 2008, J. M. Rassias [26] generalized even further the above two stabilities via a new stability involving a mixed product-sum of powers of norms, called JMRassias stability by several authors [27-30].

In the last two decades, several form of mixed type functional equation and its UlamHyers stability are dealt in various spaces like Fuzzy normed spaces, Random normed spaces, Quasi-Banach spaces, Quasinormed linear spaces and Banach algebra by various authors like [31-40].

In 1994, Cheng and Mordeson [2] introduced an idea of a fuzzy norm on a linear space whose associated metric is Kramosil and Michálek type [41]. Since then some mathematicians have defined fuzzy metrics and norms on a linear space from various points of view [42-44].

In 2001, J. M. Rassias [45] introduced the pioneering cubic functional equation in history of mathematical analysis, as follows:

$$
f(x+2 y)-3 f(x+y)+3 f(x)-f(x-y)=6 f(y)
$$

and solved the famous Ulam stability problem for this inspiring functional equation. Note that this cubic functional equation $(*)$ was the historic transition from the following famous 
Euler-Lagrange quadratic functional equation:

$$
f(x+y)-2 f(x)+f(x-y)=2 f(y)
$$

to the cubic functional equation $(*)$.

The notion of fuzzy stability of the functional equations was initiated by Mirmostafaee and Moslehian in [46]. Later, several various fuzzy versions of stability were investigated $[47,48]$. Now, let us introduce the following functional equation:

$$
f(x+3 y)-3 f(x+y)+3 f(x-y)-f(x-3 y)=48 f(y) \text {. }
$$

Since the cubic function $f(x)=c x^{3}$ satisfies in this equation, so we promise that (1.5) is called a cubic functional equation and every solution will be called a cubic function. The stability problem for the cubic functional equation was proved by Wiwatwanich and Nakmahachalasint [49] for mapping $f: E_{1} \rightarrow E_{2}$, where $E_{1}$ and $E_{2}$ are real Banach spaces. A number of mathematicians worked on the stability of some types of the cubic equation [45, 50-54]. In [55], Park and Jung introduced a cubic functional equation different from (1.5) as follows:

$$
f(x+3 y)+f(3 y-x)=3 f(x+y)+3 f(x-y)+48 f(y)
$$

and investigated the generalized Hyers-Ulam-Rassias stability for this equation on abelian groups. They also obtained results in sense of Hyers-Ulam stability and Hyers-Ulam-Rassias stability. A number of results concerning the stability of different functional equations can be found in $[23,56-59]$.

In this paper, we prove the Hyers-Ulam-Rassias stability of the cubic functional equation (1.5) in fuzzy normed spaces. Later, we will show that there exists a close relationship between the fuzzy sequentially continuity behavior of a cubic function, control function and the unique cubic mapping which approximates the cubic map.

\section{Notation and Preliminary Results}

In this section some definitions and preliminary results are given which will be used in this paper. Following [48], we give the following notion of a fuzzy norm.

Definition 2.1. Let $X$ be a linear space. A fuzzy subset $N$ of $X \times \mathbb{R}$ into $[0,1]$ is called a fuzzy norm on $X$ if for every $x, y \in X$ and $s, t \in \mathbb{R}$

(N1) $N(x, t)=0$ for $t \leq 0$,

(N2) $x=0$ if and only if $N(x, t)=1$ for all $t>0$,

(N3) $N(c x, t)=N(x, t /|c|)$ if $c \neq 0$,

(N4) $N(x+y, s+t) \geq \min \{N(x, s), N(y, t)\}$,

(N5) $N(x, \cdot)$ is a non-decreasing function on $\mathbb{R}$ and $\lim _{t \rightarrow \infty} N(x, t)=1$. 
The pair $(X, N)$ will be referred to as a fuzzy normed linear space. One may regard $N(x, t)$ as the truth value of the statement "the norm of $x$ is less than or equal to the real number $r$ ". Let $(X,\|\cdot\|)$ be a normed linear space. One can be easily verify that

$$
N(x, t)= \begin{cases}0, & t \leq\|x\|, \\ 1, & t>\|x\|\end{cases}
$$

is a fuzzy norm on $X$. Other examples of fuzzy normed linear spaces are considered in the main text of this paper.

Note that the fuzzy normed linear space $(X, N)$ is exactly a Menger probabilistic normed linear space $(X, N, T)$ where $T(a, b)=\min \{a, b\}[60]$.

Definition 2.2. A sequence $\left\{x_{n}\right\}$ in a fuzzy normed space $(X, N)$ converges to $x \in X$ (one denote $x_{n} \rightarrow x$ ) if for every $t>0$ and $\epsilon>0$, there exists a positive integer $k$ such that $N\left(x_{n}-x, t\right)>1-\epsilon$ whenever $n \geq k$.

Recall that, a sequence $\left\{x_{n}\right\}$ in $X$ is called Cauchy if for every $t>0$ and $\epsilon>0$, there exists a positive integer $k$ such that for all $n \geq k$ and all $m \in \mathbb{N}$, we have $N\left(x_{n+m}-x_{n}, t\right)>1-\epsilon$. It is known that every convergent sequence in a fuzzy normed space is Cauchy. The fuzzy normed space $(X, N)$ is said to be fuzzy Banach space if every Cauchy sequence in $X$ is convergent to a point in $X[46]$.

\section{Main Results}

We will investigate the generalized Hyers-Ulam type theorem of the functional equation (1.5) in fuzzy normed spaces. In the following theorem, we will show that under special circumstances on the control function $Q$, every $Q$-almost cubic mapping $f$ can be approximated by a cubic mapping $C$.

Theorem 3.1. Let $\alpha \in(0,27) \cup(27, \infty)$. Let $X$ be a linear space, and let $\left(Z, N^{\prime}\right)$ be a fuzzy normed space. Suppose that an even function $Q: X \times X \rightarrow Z$ satisfies $Q\left(3^{n} x, 3^{n} y\right)=\alpha^{n} Q(x, y)$ for all $x, y \in X$ and for all $n \in \mathbb{N}$. Suppose that $\left(Y, N^{\prime}\right)$ is a fuzzy Banach space. If a function $f: X \rightarrow Y$ satisfies

$$
N(f(x+3 y)-3 f(x+y)+3 f(x-y)-f(x-3 y)-48 f(y), t) \geq N^{\prime}(Q(x, y), t)
$$

for all $x, y \in X$ and $t>0$, then there exists a unique cubic function $C: X \rightarrow Y$ which satisfies (1.5) and the inequality

$$
\begin{aligned}
& N(f(x)-C(x), t) \\
& \quad \geq\left\{\begin{array}{l}
\min \left\{N^{\prime}\left(Q(0, x), \frac{(27-\alpha) t}{3}\right), N^{\prime}\left(Q(0, x), \frac{8(27-\alpha) t}{\alpha}\right)\right\}, \quad 0<\alpha<27 \\
\min \left\{N^{\prime}\left(Q(0, x), \frac{(\alpha-27) t}{3}\right), N^{\prime}\left(Q(0, x), \frac{8(\alpha-27) t}{\alpha}\right)\right\}, \quad \alpha>27
\end{array}\right.
\end{aligned}
$$

holds for all $x \in X$ and $t>0$. 
Proof. We have the following two cases.

Case $1(0<\alpha<27)$. Replacing $y$ by $-y$ in (3.1) and summing the resulting inequality with (3.1), we get

$$
N(f(y)+f(-y), t) \geq N^{\prime}(Q(x, y), 24 t) .
$$

Since (3.1) and (3.3) hold for any $x$, let us fix $x=0$ for convenience. By (N4), we have

$$
\begin{aligned}
N(2 f & (3 y)-54 f(y), t) \\
& \geq \min \left\{N^{\prime}\left(Q(0, y), \frac{t}{3}\right), N\left(f(3 y)+f(-3 y), \frac{t}{3}\right), N\left(f(y)+f(-y), \frac{t}{9}\right)\right\} \\
& \geq \min \left\{N^{\prime}\left(Q(0, y), \frac{t}{3}\right), N^{\prime}(Q(0,3 y), 8 t), N^{\prime}\left(Q(0, y), \frac{8 t}{3}\right)\right\} \\
& \geq \min \left\{N^{\prime}\left(Q(0, y), \frac{t}{3}\right), N^{\prime}\left(Q(0, y), \frac{8 t}{\alpha}\right)\right\} .
\end{aligned}
$$

Replacing $y$ by $x$ in (3.4). By (N3), we have

$$
N\left(\frac{f(3 x)}{27}-f(x), t\right) \geq \min \left\{N^{\prime}(Q(0, x), 18 t), N^{\prime}\left(Q(0, x), \frac{432 t}{\alpha}\right)\right\}
$$

Replacing $x$ by $3^{n} x$ in (3.5), we get

$$
\begin{aligned}
N\left(\frac{f\left(3^{n+1} x\right)}{27^{n+1}}-\frac{f\left(3^{n} x\right)}{27^{n}}, \frac{t}{27^{n}}\right) & \geq \min \left\{N^{\prime}\left(Q\left(0,3^{n} x\right), 18 t\right), N^{\prime}\left(Q\left(0,3^{n} x\right), \frac{432 t}{\alpha}\right)\right\} \\
& \geq \min \left\{N^{\prime}\left(Q(0, x), \frac{18 t}{\alpha^{n}}\right), N^{\prime}\left(Q(0, x), \frac{432 t}{\alpha^{n+1}}\right)\right\} .
\end{aligned}
$$

It follows from

$$
\frac{f\left(3^{n} x\right)}{27^{n}}-f(x)=\sum_{i=0}^{n-1} \frac{f\left(3^{i+1} x\right)}{27^{i+1}}-\frac{f\left(3^{i} x\right)}{27^{i}}
$$

and last inequality that

$$
\begin{aligned}
N\left(\frac{f\left(3^{n} x\right)}{27^{n}}-f(x), \sum_{i=0}^{n-1} \frac{\alpha^{i} t}{27^{i}}\right) & \geq \min \bigcup_{i=0}^{n-1}\left\{N\left(\frac{f\left(3^{i+1} x\right)}{27^{i+1}}-\frac{f\left(3^{i} x\right)}{27^{i}}, \frac{\alpha^{i} t}{27^{i}}\right)\right\} \\
& \geq \min \left\{N^{\prime}(Q(0, x), 18 t), N^{\prime}\left(Q(0, x), \frac{432 t}{\alpha}\right)\right\} .
\end{aligned}
$$


In order to prove convergence of the sequence $\left\{f\left(3^{n} x\right) / 27^{n}\right\}$, we replace $x$ by $3^{m} x$ to find that for $m, n \in \mathbb{N}$,

$$
\begin{aligned}
N\left(\frac{f\left(3^{n+m} x\right)}{27^{n+m}}-\frac{f\left(3^{m} x\right)}{27^{m}}, \sum_{i=0}^{n-1} \frac{\alpha^{i} t}{27^{i+m}}\right) & \geq \min \left\{N^{\prime}\left(Q\left(0,3^{m} x\right), 18 t\right), N^{\prime}\left(Q\left(0,3^{m} x\right), \frac{432 t}{\alpha}\right)\right\} \\
& \geq \min \left\{N^{\prime}\left(Q(0, x), \frac{18 t}{\alpha^{m}}\right), N^{\prime}\left(Q(0, x), \frac{432 t}{\alpha^{m+1}}\right)\right\} .
\end{aligned}
$$

Replacing $t$ by $\alpha^{m} t$ in last inequality to get

$$
N\left(\frac{f\left(3^{n+m} x\right)}{27^{n+m}}-\frac{f\left(3^{m} x\right)}{27^{m}}, \sum_{i=m}^{n+m-1} \frac{\alpha^{i} t}{27^{i}}\right) \geq \min \left\{N^{\prime}(Q(0, x), 18 t), N^{\prime}\left(Q(0, x), \frac{432 t}{\alpha}\right)\right\}
$$

For every $n \in \mathbb{N}$ and $m \in \mathbb{N} \cup\{0\}$, we put

$$
a_{m n}=\sum_{i=m}^{n+m-1} \frac{\alpha^{i}}{27^{i}}
$$

Replacing $t$ by $t / a_{m n}$ in last inequality, we observe that

$$
N\left(\frac{f\left(3^{n+m} x\right)}{27^{n+m}}-\frac{f\left(3^{m} x\right)}{27^{m}}, t\right) \geq \min \left\{N^{\prime}\left(Q(0, x), \frac{18 t}{a_{m n}}\right), N^{\prime}\left(Q(0, x), \frac{432 t}{\alpha a_{m n}}\right)\right\} .
$$

Let $t>0$ and $\epsilon>0$ be given. Since $\lim _{t \rightarrow \infty} N^{\prime}(Q(0, x), t)=1$, there is some $t_{1} \geq 0$ such that $N^{\prime}\left(Q(0, x), t_{2}\right)>1-\epsilon$ for every $t_{2}>t_{1}$. The convergence of the series $\sum_{i=0}^{\infty}\left(\alpha^{i} / 27^{i}\right)$ gives some $m_{1}$ such that $\min \left\{432 t / \alpha a_{m n}, 18 t / a_{m n}\right\}>t_{1}$ for every $m \geq m_{1}$ and $n \in \mathbb{N}$. For every $m \geq m_{1}$ and $n \in \mathbb{N}$, we have

$$
\begin{aligned}
N\left(\frac{f\left(3^{n+m} x\right)}{27^{n+m}}-\frac{f\left(3^{m} x\right)}{27^{m}}, t\right) & \geq \min \left\{N^{\prime}\left(Q(0, x), \frac{18 t}{a_{m n}}\right), N^{\prime}\left(Q(0, x), \frac{432 t}{\alpha a_{m n}}\right)\right\} \\
& \geq \min \{1-\epsilon, 1-\epsilon\}=1-\epsilon .
\end{aligned}
$$

This shows that $\left\{f\left(3^{n} x\right) / 27^{n}\right\}$ is a Cauchy sequence in the fuzzy Banach space $(Y, N)$, therefore this sequence converges to some point $C(x) \in Y$. Fix $x \in X$ and put $m=0$ in (3.13) to obtain

$$
N\left(\frac{f\left(3^{n} x\right)}{27^{n}}-f(x), t\right) \geq \min \left\{N^{\prime}\left(Q(0, x), \frac{18 t}{a_{0 n}}\right), N^{\prime}\left(Q(0, x), \frac{432 t}{\alpha a_{0 n}}\right)\right\} .
$$

For every $n \in \mathbb{N}$,

$$
N(C(x)-f(x), t) \geq \min \left\{N\left(C(x)-\frac{f\left(3^{n} x\right)}{27^{n}}, \frac{t}{2}\right), N\left(\frac{f\left(3^{n} x\right)}{27^{n}}-f(x), \frac{t}{2}\right)\right\} .
$$


The first two terms on the right hand side of the above inequality tend to 1 as $n \rightarrow \infty$. Therefore we have

$$
\begin{aligned}
N(C(x)-f(x), t) & \geq \min \left\{N\left(C(x)-\frac{f\left(3^{n} x\right)}{27^{n}}, \frac{t}{2}\right), N\left(\frac{f\left(3^{n} x\right)}{27^{n}}-f(x), \frac{t}{2}\right)\right\} \\
& \geq \min \left\{N^{\prime}\left(Q(0, x), \frac{9 t}{a_{0 n}}\right), N^{\prime}\left(Q(0, x), \frac{216 t}{\alpha a_{0 n}}\right)\right\}
\end{aligned}
$$

for $n$ large enough. By last inequality, we have

$$
N(C(x)-f(x), \mathrm{t}) \geq \min \left\{N^{\prime}\left(Q(0, x), \frac{(27-\alpha) t}{3}\right), N^{\prime}\left(Q(0, x), \frac{8(27-\alpha) t}{\alpha}\right)\right\} .
$$

Now, we show that $C$ is cubic. Use inequality (3.1) with $x$ replaced by $3^{n} x$ and $y$ by $3^{n} y$ to find that

$$
\begin{aligned}
& N\left(\frac{f\left(3^{n}(x+3 y)\right)}{27^{n}}-\frac{3 f\left(3^{n}(x+y)\right)}{27^{n}}+\frac{3 f\left(3^{n}(x-y)\right)}{27^{n}}-\frac{f\left(3^{n}(x-3 y)\right)}{27^{n}}-\frac{48 f\left(3^{n} y\right)}{27^{n}}, t\right) \\
& \quad \geq N^{\prime}\left(Q\left(3^{n} x, 3^{n} y\right), 27^{n} t\right)=N^{\prime}\left(Q(x, y), \frac{27^{n} t}{\alpha^{n}}\right) .
\end{aligned}
$$

On the other hand $0<\alpha<27$, hence by (N5)

$$
\lim _{n \rightarrow \infty} N^{\prime}\left(Q(x, y), \frac{27^{n} t}{\alpha^{n}}\right)=1
$$

We conclude that $C$ fulfills (1.5). It remains to prove the uniqueness assertion. Let $C^{\prime}$ be another cubic mapping satisfying (3.17). Fix $x \in X$. Obviously

$$
C\left(3^{n} x\right)=27^{n} C(x), \quad C^{\prime}\left(3^{n} x\right)=27^{n} C^{\prime}(x)
$$

for all $n \in \mathbb{N}$. For every $n \in \mathbb{N}$, we can write

$$
\begin{aligned}
N\left(C(x)-C^{\prime}(x), t\right) & =N\left(\frac{C\left(3^{n} x\right)}{27^{n}}-\frac{C^{\prime}\left(3^{n} x\right)}{27^{n}}, t\right) \\
& \geq \min \left\{N\left(\frac{C\left(3^{n} x\right)}{27^{n}}-\frac{f\left(3^{n} x\right)}{27^{n}}, \frac{t}{2}\right), N\left(\frac{f\left(3^{n} x\right)}{27^{n}}-\frac{C^{\prime}\left(3^{n} x\right)}{27^{n}}, \frac{t}{2}\right)\right\} \\
& \geq \min \left\{N^{\prime}\left(Q\left(0,3^{n} x\right), \frac{27^{n-1}(27-\alpha) 9 t}{2}\right), N^{\prime}\left(Q\left(0,3^{n} x\right), \frac{27^{n}(27-\alpha) 4 t}{\alpha}\right)\right\} \\
& \geq \min \left\{N^{\prime}\left(Q(0, x), \frac{27^{n-1}(27-\alpha) 9 t}{2 \alpha^{n}}\right), N^{\prime}\left(Q(0, x), \frac{27^{n}(27-\alpha) 4 t}{\alpha^{n+1}}\right)\right\} .
\end{aligned}
$$


Since $0<\alpha<27$, we have

$$
\lim _{n \rightarrow \infty} N^{\prime}\left(Q(0, x), \frac{27^{n-1}(27-\alpha) 9 t}{2 \alpha^{n}}\right)=N^{\prime}\left(Q(0, x), \frac{27^{n}(27-\alpha) 4 t}{\alpha^{n+1}}\right)=1 .
$$

Therefore $N^{\prime}\left(C(x)-C^{\prime}(x), t\right)=1$ for all $t>0$, whence $C(x)=C^{\prime}(x)$.

Case $2(27<\alpha)$. We can state the proof in the same pattern as we did in the first case. Replace $x, t$ by $x / 3$ and $2 t$, respectively in (3.4) to get

$$
N^{\prime}\left(f(x)-27 f\left(\frac{x}{3}\right), t\right) \geq \min \left\{N^{\prime}\left(Q\left(0, \frac{x}{3}\right), \frac{2 t}{3}\right), N^{\prime}\left(Q\left(0, \frac{x}{3}\right), \frac{16 t}{\alpha}\right)\right\} .
$$

We replace $y$ and $t$ by $x / 3^{n}$ and $t / 27^{n}$ in last inequality, respectively, we find that

$$
\begin{aligned}
& N\left(27^{n} f\left(\frac{x}{3^{n}}\right)-27^{n+1} f\left(\frac{x}{3^{n+1}}\right), t\right) \\
& \geq \min \left\{N^{\prime}\left(Q\left(0, \frac{x}{3^{n+1}}\right), \frac{2 t}{3 \times 27^{n}}\right), N^{\prime}\left(Q\left(0, \frac{x}{3^{n+1}}\right), \frac{16 t}{27^{n} \alpha}\right)\right\} \\
& \quad \geq \min \left\{N^{\prime}\left(Q(0, x), \frac{2 \alpha^{n+1} t}{3 \times 27^{n}}\right), N^{\prime}\left(Q(0, x), \frac{16 \alpha^{n} t}{27^{n}}\right)\right\} .
\end{aligned}
$$

For each $n \in \mathbb{N}$, one can deduce

$$
N\left(27^{n} f\left(\frac{x}{3^{n}}\right)-f(x), t\right) \geq \min \left\{N^{\prime}\left(Q(0, x), \frac{2 \alpha t}{3 b_{0 n}}\right), N^{\prime}\left(Q(0, x), \frac{16 t}{b_{0 n}}\right)\right\}
$$

where $b_{0 n}=\sum_{i=0}^{n-1}\left(27^{i} / \alpha^{i}\right)$. It is easy to see that $\left\{27^{n} f\left(x / 3^{n}\right)\right\}$ is a Cauchy sequence in $(Y, N)$. Since $(Y, N)$ is a fuzzy Banach space, this sequence converges to some point $C(x) \in Y$, that is,

$$
C(x)=\lim _{n \rightarrow \infty} 27^{n} f\left(\frac{x}{3^{n}}\right) .
$$

Moreover, $C$ satisfies (1.5) and

$$
N(f(x)-C(x), t) \geq \min \left\{N^{\prime}\left(Q(0, x), \frac{(\alpha-27) t}{3}\right), N^{\prime}\left(Q(0, x), \frac{8(\alpha-27) t}{\alpha}\right)\right\}
$$

The proof for uniqueness of $C$ for this case proceeds similarly to that in the previous case, hence it is omitted.

We note that $\alpha$ need not be equal to 27 . But we do not guarantee whether the cubic equation is stable in the sense of Hyers, Ulam and Rassias if $\alpha=27$ is assumed in Theorem 3.1. 
Remark 3.2. Let $0<\alpha<27$. Suppose that the mapping $t \mapsto N(Q(x)-f(x), \cdot)$ from $(0, \infty)$ into $[0,1]$ is right continuous. Then we get a fuzzy approximation better than (3.17) as follows.

For every $s, t>0$, we have

$$
\begin{aligned}
N(C(x)-f(x), s+t) & \geq \min \left\{N\left(C(x)-\frac{f\left(3^{n} x\right)}{27^{n}}, s\right), N\left(\frac{f\left(3^{n} x\right)}{27^{n}}-f(x), t\right)\right\} \\
& \geq \min \left\{N^{\prime}\left(Q(0, x), \frac{18 t}{a_{0 n}}\right), N^{\prime}\left(Q(0, x), \frac{432 t}{\alpha a_{0 n}}\right)\right\}
\end{aligned}
$$

for large enough $n$. It follows that

$$
N(C(x)-f(x), s+t) \geq \min \left\{N^{\prime}\left(Q(0, x), \frac{2(27-\alpha) t}{3}\right), N^{\prime}\left(Q(0, x), \frac{16(27-\alpha) t}{\alpha}\right)\right\} .
$$

Tending $s$ to zero we infer

$$
N(C(x)-f(x), t) \geq \min \left\{N^{\prime}\left(Q(0, x), \frac{2(27-\alpha) t}{3}\right), N^{\prime}\left(Q(0, x), \frac{16(27-\alpha) t}{\alpha}\right)\right\}
$$

From Theorem 3.1, we obtain the following corollary concerning the stability of (1.5) in the sense of the JMRassias stability of functional equations controlled by the mixed productsum of powers of norms introduced by J. M. Rassias [26] and called JMRassias stability by several authors [27-30].

Corollary 3.3. Let $X$ be a Banach space and let $\epsilon>0$ be a real number. Suppose that a function $f: X \rightarrow X$ satisfies

$$
\|f(x+3 y)-3 f(x+y)+3 f(x-y)-f(x-3 y)-48 f(y)\| \leq \epsilon\left(\|x\|^{p}\|y\|^{p}+\|x\|^{2 p}+\|y\|^{2 p}\right)
$$

for all $x, y \in X$ where $0 \leq p<1 / 2$. Then there exists a unique cubic function $C: X \rightarrow X$ which satisfying (1.5) and the inequality

$$
\|C(x)-f(x)\| \leq \frac{\|x\|^{p} \epsilon}{8}
$$

for all $x \in X$. The function $C: X \rightarrow X$ is given by $C(x)=\lim _{n \rightarrow \infty} f\left(3^{n} x\right) / 27^{n}$ for all $x \in X$.

Proof. Define $N: X \times \mathbb{R} \rightarrow[0,1]$ by

$$
N(x, t)= \begin{cases}\frac{t}{t+\|x\|}, & t>0 \\ 0, & t \leq 0\end{cases}
$$


It is easy to see that $(X, N)$ is a fuzzy Banach space. Denote by $Q: X \times X \rightarrow \mathbb{R}$ the map sending each $(x, y)$ to $\epsilon\left(\|x\|^{p}\|y\|^{p}+\|x\|^{2 p}+\|y\|^{2 p}\right)$. By assumption,

$$
N(f(x+3 y)-3 f(x+y)+3 f(x-y)-f(x-3 y)-48 f(y), t) \geq N^{\prime}(Q(x, y), t) .
$$

Note that $N^{\prime}: \mathbb{R} \times \mathbb{R} \rightarrow[0,1]$ given by

$$
N^{\prime}(x, t)= \begin{cases}\frac{t}{t+\|x\|}, & t>0 \\ 0, & t \leq 0\end{cases}
$$

is a fuzzy norm on $\mathbb{R}$. By Theorem 3.1, there exists a unique cubic function $C: X \rightarrow X$ satisfies (1.5) and inequality

$$
\begin{aligned}
\frac{t}{t+\|f(x)-C(x)\|} & =N(f(x)-C(x), t) \\
& \geq \min \left\{N^{\prime}(Q(0, x), 8 t), N^{\prime}(Q(0, x), 64 t)\right\} \\
& =\min \left\{\frac{8 t}{8 t+\epsilon\|x\|}, \frac{64 t}{64 t+\epsilon\|x\|}\right\} \\
& =\frac{8 t}{8 t+\epsilon\|x\|}
\end{aligned}
$$

for all $x \in X$ and $t>0$. Consequently, $8\|f(x)-C(x)\| \leq\|x\| \epsilon$.

Definition 3.4. Let $f:(X, N) \rightarrow\left(Y, N^{\prime}\right)$ be a mapping where $(X, N)$ and $\left(Y, N^{\prime}\right)$ are fuzzy normed spaces. $f$ is said to be sequentially fuzzy continuous at $x \in \mathrm{X}$ if for any $x_{n} \in \mathrm{X}$ satisfying $x_{n} \rightarrow x$ implies $f\left(x_{n}\right) \rightarrow f(x)$. If $f$ is sequentially fuzzy continuous at each point of $X$, then $f$ is said to be sequentially fuzzy continuous on $X$.

For the various definitions of continuity and also defining a topology on a fuzzy normed space we refer the interested reader to $[61,62]$. Now we examine some conditions under which the cubic mapping found in Theorem 3.1 to be continuous. In the following theorem, we investigate fuzzy sequentially continuity of cubic mappings in fuzzy normed spaces. Indeed, we will show that under some extra conditions on Theorem 3.1, the cubic mapping $r \mapsto Q(r x)$ is fuzzy sequentially continuous.

Theorem 3.5. Denote $N_{1}$ the fuzzy norm obtained as Corollary 3.3 on $\mathbb{R}$. Suppose that conditions of Theorem 3.1 hold. If for every $x \in X$ the mappings $r \mapsto f(r x)$ (from $\left(\mathbb{R}, N_{1}\right)$ into $(Y, N)$ ) and $r \mapsto Q(0, r x)$ (from $\left(\mathbb{R}, N_{1}\right)$ into $\left(Z, N^{\prime}\right)$ ) are sequentially fuzzy continuous, then the mapping $r \mapsto$ $C(r x)$ is sequentially continuous and $C(r x)=r^{3} C(x)$ for all $r \in \mathbb{R}$. 
Proof. We have the following case.

Case $1(0<\alpha<27)$. Let $\left\{r_{n}\right\}$ be a sequence in $\mathbb{R}$ that converges to some $r \in \mathbb{R}$, and let $t>0$. Let $\epsilon>0$ be given. Since $0<\alpha<27$,

$$
\lim _{n \rightarrow \infty} \frac{(27-\alpha) 27^{n} t}{18 \alpha^{n}}=\lim _{n \rightarrow \infty} \frac{8(27-\alpha) 27^{n} t}{6 \alpha^{n+1}}=\infty,
$$

there is $m \in \mathbb{N}$ such that

$$
\min \left\{N^{\prime}\left(Q(0, r x), \frac{(27-\alpha) 27^{m} t}{18 \alpha^{m}}\right), N^{\prime}\left(Q(0, r x), \frac{8(27-\alpha) 27^{m} t}{6 \alpha^{m+1}}\right)\right\}>1-\epsilon
$$

It follows form (3.17) and (3.38) that

$$
N\left(\frac{f\left(3^{m} r x\right)}{27^{m}}-\frac{C\left(3^{m} r x\right)}{27^{m}}, \frac{t}{3}\right)>1-\epsilon .
$$

By the sequentially fuzzy continuity of maps $r \mapsto Q(0, r x)$ and $r \mapsto f(r x)$, we can find some $k \in \mathbb{N}$ such that for any $n \geq k$,

$$
N\left(\frac{f\left(3^{m} r_{n} x\right)}{27^{m}}-\frac{f\left(3^{m} r x\right)}{27^{m}}, \frac{t}{3}\right)>1-\epsilon
$$

and

$$
\begin{aligned}
\min & \left\{N^{\prime}\left(Q\left(0, r_{n} x\right)-Q(0, r x), \frac{(27-\alpha) 27^{m} t}{18 \alpha^{m}}\right), N^{\prime}\left(Q\left(0, r_{n} x\right)-Q(0, r x), \frac{8(27-\alpha) 27^{m} t}{6 \alpha^{m+1}}\right)\right\} \\
& >1-\epsilon .
\end{aligned}
$$

Hence by last inequality and (3.38), we get

$$
\min \left\{N^{\prime}\left(Q\left(0, r_{n} x\right), \frac{(27-\alpha) 27^{m} t}{9 \alpha^{m}}\right), N^{\prime}\left(Q\left(0, r_{n} x\right), \frac{8(27-\alpha) 27^{m} t}{3 \alpha^{m+1}}\right)\right\}>1-\epsilon
$$

On the other hand,

$$
\begin{aligned}
N\left(C\left(r_{n} x\right)-\frac{f\left(3^{m} r_{n} x\right)}{27^{m}}, \frac{t}{27^{m}}\right) & =N\left(\frac{C\left(3^{m} r_{n} x\right)}{27^{m}}-\frac{f\left(3^{m} r_{n} x\right)}{27^{m}}, \frac{t}{27^{m}}\right) \\
& \geq \min \left\{N^{\prime}\left(Q\left(0, r_{n} x\right), \frac{(27-\alpha) t}{3 \alpha^{m}}\right), N^{\prime}\left(Q\left(0, r_{n} x\right), \frac{8(27-\alpha) t}{\alpha^{m+1}}\right)\right\}
\end{aligned}
$$


Hence by last inequality and (3.42), we obtain

$$
N\left(C\left(r_{n} x\right)-\frac{f\left(3^{m} r_{n} x\right)}{27^{m}}, \frac{t}{3}\right)>1-\epsilon .
$$

Therefore it follows from (3.44), (3.40) and (3.39) that for every $n \geq k$,

$$
N\left(C\left(r_{n} x\right)-C(r x), t\right)>1-\epsilon .
$$

Therefore for every choice $x \in X, t>0$ and $\epsilon>0$, we can find some $k \in \mathbb{N}$ such that $N\left(C\left(r_{n} x\right)\right.$ $C(r x), t)>1-\epsilon$ for every $n \geq k$. This shows that $C\left(r_{n} x\right) \rightarrow C(r x)$.

The proof for $p>27$ proceeds similarly to that in the previous case.

It is not hard to see that $C(r x)=r^{3} C(x)$ for every rational number $r$. Since $C$ is a fuzzy sequentially continuous map, by the same reasoning as the proof of [46], the cubic function $C: X \rightarrow X$ satisfies $C(r x)=r^{3} C(x)$ for every $r \in \mathbb{R}$.

The following corollary is the Hyers-Ulam stability [7] of (1.5).

Corollary 3.6. Let $X$ be a Banach space, and let $\epsilon>0$ be a real number. Suppose that a function $f: X \rightarrow X$ satisfies

$$
\|f(x+3 y)-3 f(x+y)+3 f(x-y)-f(x-3 y)-48 f(y)\| \leq \epsilon
$$

for all $x, y \in X$. Then there exists a unique cubic function $C: X \rightarrow X$ which satisfies (1.5) and the inequality

$$
\|C(x)-f(x)\| \leq \frac{3 \epsilon}{26}
$$

for all $x \in X$. Moreover, if for each fixed $x \in X$ the mapping $t \rightarrow f(t x)$ from $\mathbb{R}$ to $X$ is fuzzy sequentially continuous, then $C(r x)=r^{3} C(x)$ for all $r \in \mathbb{R}$.

Proof. Denote $N$ and $N^{\prime}$ the fuzzy norms obtained as Corollary 3.3 on $X$ and $\mathbb{R}$, respectively. This time we choose $Q(x, y)=\epsilon$. By Theorem 3.1, there exists a unique cubic function $C$ : $X \rightarrow X$ which satisfies the inequality

$$
N(f(x)-C(x), t) \geq \min \left\{N^{\prime}\left(\epsilon, \frac{26 t}{3}\right), N^{\prime}(\epsilon, 8 \times 26 t)\right\}=N^{\prime}\left(\epsilon, \frac{26 t}{3}\right)
$$

for all $x \in X$. It follows that $\|f(x)-C(x)\| \leq 3 \epsilon / 26$. The rest of proof is an immediate consequence of Theorem 3.5.

\section{Acknowledgments}

The second author would like to thank the office of gifted students at the Semnan university for financial support. 


\section{References}

[1] A. K. Katsaras, "Fuzzy topological vector spaces. II," Fuzzy Sets and Systems, vol. 12, no. 2, pp. 143-154, 1984.

[2] S. C. Cheng and J. N. Mordeson, "Fuzzy linear operators and fuzzy normed linear spaces," Bulletin of the Calcutta Mathematical Society, vol. 86, no. 5, pp. 429-436, 1994.

[3] A. Chitra and P. V. Subrahmanyam, "Fuzzy sets and fixed points," Journal of Mathematical Analysis and Applications, vol. 124, no. 2, pp. 584-590, 1987.

[4] T. Bag and S. K. Samanta, "Finite dimensional fuzzy normed linear spaces," Journal of Fuzzy Mathematics, vol. 11, no. 3, pp. 687-705, 2003.

[5] T. Bag and S. K. Samanta, "Fuzzy bounded linear operators," Fuzzy Sets and Systems, vol. 151, no. 3, pp. 513-547, 2005.

[6] S. M. Ulam, Problems in Modern Mathematics, chapter VI, John Wiley \& Sons, New York, NY, USA, 1964.

[7] D. H. Hyers, "On the stability of the linear functional equation," Proceedings of the National Academy of Sciences of the United States of America, vol. 27, pp. 222-224, 1941.

[8] T. Aoki, "On the stability of the linear transformation in Banach spaces," Journal of the Mathematical Society of Japan, vol. 2, pp. 64-66, 1950.

[9] T. M. Rassias, "On the stability of the linear mapping in Banach spaces," Proceedings of the American Mathematical Society, vol. 72, no. 2, pp. 297-300, 1978.

[10] J. M. Rassias, “On approximation of approximately linear mappings by linear mappings," Journal of Functional Analysis, vol. 46, no. 1, pp. 126-130, 1982.

[11] H.-M. Kim, J. M. Rassias, and Y.-S. Cho, "Stability problem of Ulam for Euler-Lagrange quadratic mappings," Journal of Inequalities and Applications, vol. 2007, Article ID 10725, 15 pages, 2007.

[12] J. M. Rassias, "Complete solution of the multi-dimensional problem of Ulam," Discussiones Mathematicae, vol. 14, pp. 101-107, 1994.

[13] A. Pietrzyk, "Stability of the Euler-Lagrange-Rassias functional equation," Demonstratio Mathematica, vol. 39, no. 3, pp. 523-530, 2006.

[14] Y.-S. Lee and S.-Y. Chung, "Stability of an Euler-Lagrange-Rassias equation in the spaces of generalized functions," Applied Mathematics Letters, vol. 21, no. 7, pp. 694-700, 2008.

[15] J. M. Rassias and M. J. Rassias, "On some approximately quadratic mappings being exactly quadratic," The Journal of the Indian Mathematical Society, vol. 69, no. 1-4, pp. 155-160, 2002.

[16] C. Park and J. M. Rassias, "Stability of the Jensen-type functional equation in $C^{*}$-algebras: a fixed point approach," Abstract and Applied Analysis, vol. 2009, Article ID 360432, 17 pages, 2009.

[17] M. E. Gordji, J. M. Rassias, and N. Ghobadipour, “Generalized Hyers-Ulam stability of generalized (N,K)-derivations," Abstract and Applied Analysis, vol. 2009, Article ID 437931, 8 pages, 2009.

[18] M. E. Gordji, S. K. Gharetapeh, J. M. Rassias, and S. Zolfaghari, "Solution and stability of a mixed type additive, quadratic, and cubic functional equation," Advances in Difference Equations, vol. 2009, Article ID 826130, 17 pages, 2009.

[19] M. E. Gordji, J. M. Rassias, and M. B. Savadkouhi, "Approximation of the quadratic and cubic functional equations in RN-spaces," European Journal of Pure and Applied Mathematics, vol. 2, no. 4, pp. 494-507, 2009.

[20] J. M. Rassias, "Solution of the Ulam stability problem for quartic mappings," Glasnik Matematički. Serija III, vol. 34(54), no. 2, pp. 243-252, 1999.

[21] B. Bouikhalene, E. Elqorachi, and J. M. Rassias, “The superstability of d'Alembert's functional equation on the Heisenberg group," Applied Mathematics Letters, vol. 23, no. 1, pp. 105-109, 2010.

[22] M. B. Savadkouhi, M. E. Gordji, J. M. Rassias, and N. Ghobadipour, "Approximate ternary Jordan derivations on Banach ternary algebras," Journal of Mathematical Physics, vol. 50, no. 4, Article ID 042303, 9 pages, 2009.

[23] J. M. Rassias, "Solution of a stability problem of Ulam," Discussiones Mathematicae, vol. 12, pp. 95-103, 1992.

[24] M. J. Rassias and J. M. Rassias, “On the Ulam stability for Euler-Lagrange type quadratic functional equations," The Australian Journal of Mathematical Analysis and Applications, vol. 2, no. 1, pp. 1-10, 2005.

[25] J. M. Rassias and M. J. Rassias, "On the Ulam stability of Jensen and Jensen type mappings on restricted domains," Journal of Mathematical Analysis and Applications, vol. 281, no. 2, pp. 516-524, 2003. 
[26] K. Ravi, M. Arunkumar, and J. M. Rassias, "Ulam stability for the orthogonally general EulerLagrange type functional equation," International Journal of Mathematics and Statistics, vol. 3, no. 8, pp. 36-46, 2008.

[27] M. E. Gordji, S. Zolfaghari, J. M. Rassias, and M. B. Savadkouhi, "Solution and stability of a mixed type cubic and quartic functional equation in quasi-Banach spaces," Abstract and Applied Analysis, vol. 2009, Article ID 417473, 14 pages, 2009.

[28] M. E. Gordji and H. Khodaei, "On the generalized Hyers-Ulam-Rassias stability of quadratic functional equations," Abstract and Applied Analysis, vol. 2009, Article ID 923476, 11 pages, 2009.

[29] H.-X. Cao, J.-R. Lv, and J. M. Rassias, "Superstability for generalized module left derivations and generalized module derivations on a Banach module (I)," Journal of Inequalities and Applications, vol. 2009, Article ID 718020, 10 pages, 2009.

[30] H.-X. Cao, J.-R. Lv, and J. M. Rassias, "Superstability for generalized module left derivations and generalized module derivations on a Banach module (II)," Journal of Inequalities in Pure and Applied Mathematics, vol. 10, no. 3, article 85, pp. 1-8, 2009.

[31] P. Gavruta, "An answer to a question of John M. Rassias concerning the stability of Cauchy equation," in Advances in Equations and Inequalities, Hadronic Mathematic Series, pp. 67-71, 1999.

[32] P. Nakmahachalasint, "On the generalized Ulam-Gavruta-Rassias stability of mixed-type linear and Euler-Lagrange-Rassias functional equations," International Journal of Mathematics and Mathematical Sciences, vol. 2007, Article ID 63239, 10 pages, 2007.

[33] K.-W. Jun, H.-M. Kim, and J. M. Rassias, “Extended Hyers-Ulam stability for Cauchy-Jensen mappings," Journal of Difference Equations and Applications, vol. 13, no. 12, pp. 1139-1153, 2007.

[34] V. Faĭziev and J. M. Rassias, "Stability of generalized additive equations on Banach spaces and groups," Journal of Nonlinear Functional Analysis and Differential Equations, vol. 1, no. 2, pp. 153-173, 2007.

[35] J. M. Rassias, J. Lee, and H. M. Kim, "Refined Hyers-Ulam stability for Jensen type mappings," Journal of the Chungcheong Mathematical Society, vol. 22, no. 1, pp. 101-116, 2009.

[36] K. Ravi and M. Arunkumar, "On the Ulam-Gavruta-Rassias stability of the orthogonally EulerLagrange type functional equation," International Journal of Applied Mathematics \& Statistics, vol. 7, no. 7, pp. 143-156, 2007.

[37] P. Nakmahachalasint, "Hyers-Ulam-Rassias and Ulam-Gavruta-Rassias stabilities of an additive functional equation in several variables," International Journal of Mathematics and Mathematical Sciences, vol. 2007, Article ID 13437, 6 pages, 2007.

[38] M. Ait SiBaha, B. Bouikhalene, and E. Elqorachi, "Ulam-Gavruta-Rassias stability of a linear functional equation," International Journal of Applied Mathematics E Statistics, vol. 7, no. 7, pp. 157166, 2007.

[39] B. Belaid and E. Elqorachi, "Ulam-Găvruta-Rassias stability of the Pexider functional equation," International Journal of Applied Mathematics E Statistics, vol. 7, no. 7, pp. 27-39, 2007.

[40] K. Ravi, J. M. Rassias, M. Arunkumar, and R. Kodandan, "Stability of a generalized mixed type additive, quadratic, cubic and quartic functional equation," Journal of Inequalities in Pure and Applied Mathematics, vol. 10, no. 4, article 114, pp. 1-29, 2009.

[41] I. Kramosil and J. Michálek, "Fuzzy metrics and statistical metric spaces," Kybernetika, vol. 11, no. 5, pp. 336-344, 1975.

[42] C. Felbin, "Finite-dimensional fuzzy normed linear space," Fuzzy Sets and Systems, vol. 48, no. 2, pp. 239-248, 1992.

[43] P. V. Subrahmanyam, "A common fixed point theorem in fuzzy metric spaces," Information Sciences, vol. 83, no. 3-4, pp. 109-112, 1995.

[44] J. Xiao and X. Zhu, "Topological degree theory and fixed point theorems in fuzzy normed space," Fuzzy Sets and Systems, vol. 147, no. 3, pp. 437-452, 2004.

[45] J. M. Rassias, "Solution of the Ulam stability problem for cubic mappings," Glasnik Matematički. Serija III, vol. 36(56), no. 1, pp. 63-72, 2001.

[46] A. K. Mirmostafaee and M. S. Moslehian, "Fuzzy approximately cubic mappings," Information Sciences, vol. 178, no. 19, pp. 3791-3798, 2008.

[47] A. K. Mirmostafaee and M. S. Moslehian, "Fuzzy versions of Hyers-Ulam-Rassias theorem," Fuzzy Sets and Systems, vol. 159, no. 6, pp. 720-729, 2008.

[48] A. K. Mirmostafaee, M. Mirzavaziri, and M. S. Moslehian, "Fuzzy stability of the Jensen functional equation," Fuzzy Sets and Systems, vol. 159, no. 6, pp. 730-738, 2008. 
[49] A. Wiwatwanich and P. Nakmahachalasint, "On the stability of a cubic functional equation," Thai Journal of Mathematics, vol. 6, no. 3, pp. 69-76, 2008.

[50] M. Eshaghi Gordji and M. Bavand Savadkouhi, "Stability of mixed type cubic and quartic functional equations in random normed spaces," Journal of Inequalities and Applications, vol. 2009, Article ID 527462, 9 pages, 2009.

[51] S.-M. Jung, Hyers-Ulam-Rassias Stability of Functional Equations in Mathematical Analysis, Hadronic Press, Palm Harbor, Fla, USA, 2001.

[52] M. S. Moslehian and G. Sadeghi, "Stability of two types of cubic functional equations in nonArchimedean spaces," Real Analysis Exchange, vol. 33, no. 2, pp. 375-383, 2008.

[53] M. Eshaghi, S. Kaboli-Gheretapeh, M. S. Moslehian, and S. Zolfaghari, "Stability of a mixed type additive, quadratic, cubic and quartic functional equation," in Nonlinear Analysis and Variational Problems, P. M. Pardalos, T. M. Rassias, and A. A. Khan, Eds., Springer Optimization and Its Applications, 35, Springer, Berlin, Germany, 2009.

[54] T. M. Rassias, Ed., Functional Equations and Inequalities, vol. 518 of Mathematics and Its Applications, Kluwer Academic Publishers, Dordrecht, The Netherlands, 2000.

[55] K.-H. Park and Y.-S. Jung, "Stability of a cubic functional equation on groups," Bulletin of the Korean Mathematical Society, vol. 41, no. 2, pp. 347-357, 2004.

[56] J. M. Rassias, "On the stability of the Euler-Lagrange functional equation," Chinese Journal of Mathematics, vol. 20, no. 2, pp. 185-190, 1992.

[57] J. M. Rassias and M. J. Rassias, "Asymptotic behavior of alternative Jensen and Jensen type functional equations," Bulletin des Sciences Mathématiques, vol. 129, no. 7, pp. 545-558, 2005.

[58] J. M. Rassias and H.-M. Kim, "Approximate homomorphisms and derivations between $C^{*}$-ternary algebras," Journal of Mathematical Physics, vol. 49, no. 6, 10 pages, 2008.

[59] C. Park and J. M. Rassias, "Stability of the Jensen-type functional equation in $C^{*}$-algebras: a fixed point approach," Abstract and Applied Analysis, vol. 2009, Article ID 360432, 17 pages, 2009.

[60] A. Ghaffari, A. Alinejad, and M. Eshaghi Gordji, "On the stability of general cubic-quartic functional equations in Menger probabilistic normed spaces," Journal of Mathematical Physics, vol. 50, no. 12, 7 pages, 2009.

[61] T. Bag and S. K. Samanta, "Product fuzzy normed linear spaces," Journal of Fuzzy Mathematics, vol. 13, no. 3, pp. 545-565, 2005.

[62] T. Bag and S. K. Samanta, "Fixed point theorems on fuzzy normed linear spaces," Information Sciences, vol. 176, no. 19, pp. 2910-2931, 2006. 